University of Wollongong

Research Online

January 2020

Lowering the Walls: An Integrative Approach to First Year Undergraduate Business Education

Mario Fernando

University of Wollongong, mariof@uow.edu.au

Stephen Fox

Ruwan Bandara

University of Wollongong

Daniel Hartley

Follow this and additional works at: https://ro.uow.edu.au/balpapers

Research Online is the open access institutional repository for the University of Wollongong. For further information contact the UOW Library: research-pubs@uow.edu.au 


\title{
Lowering the Walls: An Integrative Approach to First Year Undergraduate Business Education
}

\begin{abstract}
Purpose: The aim of this study is to examine the nature of interdisciplinary thinking and the conditions and processes that foster it amongst first year undergraduate students. Methodology: This study with 510 Australian students drawn from two cohorts explored an initiative to promote interdisciplinary teaching in an undergraduate ethics-based subject. The study focused on a case study-based reflective essay intervention to compare the teaching and learning outcomes in the two student cohorts. Findings: The results show how a case study-based reflective essay intervention impacted on interdisciplinary learning. Introducing the case-study-based reflective essay improved interdisciplinary thinking. Findings show that integral to engaging students in interdisciplinary learning is a need for more experiential and active approaches built into education itself. Research limitations/implications: The study findings extend Spelt et al.'s (2009) model in the business education context to link student learning outcomes to the learning processes, learning environment and interdisciplinary thinking. A key limitation of this study is that the intervention is limited to only two student cohorts. Practical implications: The study recommends the use of reflective practice in interdisciplinary subjects to support a variety of learning outcomes across disciplines including classroom-based and assignment-based reflective practices which influence interdisciplinary thinking and active learning. Originality/value: There is limited understanding on how business schools should or could attempt to promote interdisciplinary teaching and the actual methods for doing so. This study highlights the significance of integrating reflective practice in undergraduate business education to promote students' interdisciplinary thinking.

\section{Publication Details}

Fernando, M., Fox, S., Bandara, R. \& Hartley, D. (2020). Lowering the Walls: An Integrative Approach to First Year Undergraduate Business Education. Journal of International Education in Business, online first 1-21.
\end{abstract}




\title{
Lowering the Walls: An Integrative Approach to First Year Undergraduate Business
}

\section{Education}

\begin{abstract}
Purpose: The aim of this study is to examine the nature of interdisciplinary thinking and the conditions and processes that foster it amongst first year undergraduate students. Methodology: This study with 510 Australian students drawn from two cohorts explored an initiative to promote interdisciplinary teaching in an undergraduate ethics-based subject. The study focused on a case study-based reflective essay intervention to compare the teaching and learning outcomes in the two student cohorts.
\end{abstract}

Findings: The results show how a case study-based reflective essay intervention impacted on interdisciplinary learning. Introducing the case-study-based reflective essay improved interdisciplinary thinking. Findings show that integral to engaging students in interdisciplinary learning is a need for more experiential and active approaches built into education itself.

Research limitations/implications: The study findings extend Spelt et al.'s (2009) model in the business education context to link student learning outcomes to the learning processes, learning environment and interdisciplinary thinking. A key limitation of this study is that the intervention is limited to only two student cohorts.

Practical implications: The study recommends the use of reflective practice in interdisciplinary subjects to support a variety of learning outcomes across disciplines including classroom-based and assignment-based reflective practices which influence interdisciplinary thinking and active learning.

Originality/value: There is limited understanding on how business schools should or could attempt to promote interdisciplinary teaching and the actual methods for doing so. This study 
highlights the significance of integrating reflective practice in undergraduate business education to promote students' interdisciplinary thinking.

Article Classification: Research paper

Keywords: Reflective practice, Interdisciplinary education, First year undergraduate business education 


\section{Introduction}

Lindvig and Ulriksen (2020) call for more empirical studies of interdisciplinary teaching activities. According to Currie et al. (2016), the time is right to examine the success stories of interdisciplinary collaboration. They particularly emphasize the need to examine the "lowering of walls" between disciplines for interdisciplinary collaboration. While we generally agree with their argument on interdisciplinary research (IDR), the present paper focuses on interdisciplinary teaching, education and learning (IDTEL). This area of interdisciplinary collaboration has been growing across higher education especially since the OECD's (1972) report: Interdisciplinarity: Problems of Teaching and Research in Universities. Some argue that the focus on interdisciplinarity originated mainly from the insights drawn from systems thinking and the General Systems Theory (Ackoff and Emery, 1972).

Different countries have adopted different stances on interdisciplinary education (IDE). Lindvig and Ulriksen (2020) found that American and Australian contexts constitute the vast majority of higher education institutes leaning towards a generalized image of interdisciplinarity, a contrast from most European higher-education systems. Lattuca et al. (2004) about higher education (HE) in general, inform us that although nearly $40 \%$ of faculty has taught an interdisciplinary course but evidence of the impact of these courses on student learning is sparse. Only a few studies at the college level lend support to the idea that interdisciplinary study has positive effects on learning. Some studies of interdisciplinary courses have appeared but few within business schools. However, as the rate of growth in interdisciplinary education has begun to speed up, increasingly entire universities have developed organization-wide policy interventions with the aim of creating interdisciplinary programs. For instance, Brint et al. (2009, p. 155) examine the growth of "interdisciplinary fields" across American higher education from 1975-2000, and state that "the growth of interdisciplinary research and teaching is now widely recognized as a notable feature of 
academic change over the last thirty years." Although there have been calls for “interdisciplinary management studies" (Clegg and Ross-Smith, 2003; Currie et al., 2016), the question of what an interdisciplinary education in business and management might mean remains uncertain although there are examples (Buttermore, 2011; Ducoffe et al., 2006; Shay, 2016) and some critics who argue that interdisciplinarity should not be promoted by compromising depth of specialized learning (Campbell et al., 2006).

Lattuca et al. (2004, p. 23) note that champions of interdisciplinary courses promote them as "more engaging than disciplinary courses" mainly because "they capture students" intellectual interest and help them connect information from discrete disciplines" and that these courses "better prepare students for work and citizenship by developing higher-order cognitive skills such as problem-solving, critical thinking, and the ability to employ multiple perspectives." Several American initiatives seem to have followed these expectations but with mixed results (Buttermore, 2011; Campbell et al., 2006; Ducoffe et al., 2006). However, the lack of empirical evidence of interdisciplinary teaching and learning has been highlighted for some time (Lindvig and Ulriksen, 2020). In particular, there is limited literature on how business schools should or could attempt to promote interdisciplinary teaching and the actual methods for doing so.

Studies of interdisciplinary higher education (IDHE) have looked at several facets of the phenomenon, focusing on: the nature of "interdisciplinary thinking" (e.g., Mansilla and Duraising, 2007); the organizational change process (Millar, 2016; Ryan and Neumann, 2013); the growth of interdisciplinary degree granting academic fields (Brint et al., 2009); the organization, characteristics and outcomes of interdisciplinary courses (Lattuca et al., 2004); the importance of building team culture to give interdisciplinary teaching collaborations integrity and sustainability (Neill, Corder and Cox, 2017) and the assessment of interdisciplinary work (Mansilla and Duraising, 2007). 
This study in Australia explored an initiative to promote interdisciplinary teaching in an undergraduate ethics-based subject COMM101 taught by the Faculty of Business. The paper contributes to the debate on interdisciplinary teaching and learning in business and management studies within higher education. It specifically addresses student experience through a study based on student self-reporting about the interdisciplinary subject COMM101. The study reflects on interdisciplinarity, as it has been developed in this university context and draws from a theoretical framework developed by Spelt et al. (2009) which links student learning outcomes to the learning processes, learning environment and interdisciplinary thinking. Student engagement is not incorporated into Spelt at al.'s (2009) framework by explicit design; rather, it is expected to emerge from the implementation of the framework. That is, for Spelt et al., student engagement is an emergent rather than a designed aspect in the learning process. By engaging the emotional dimension of student engagement, we examine how a case-study-based reflective essay can encourage students to use their affective capacities to extrapolate what they learn from case studies in a creative way to similar situations (Moon, 2006). Students in COMM101 can be engaged in various ways. Based on Kolb's (2014) model of experiential learning and associated learning styles of assimilator, converger, accommodator and diverger, COMM101 focus on engaging students by encouraging them to primarily ask 'why' questions, where the teacher is the motivator (Healey et al., 2005). Students in this approach view concrete situations from multiple perspectives, with hypothetical thinking and feelings playing a central part in the learning process. Learning by experience, discussion and reflection are emphasized. Assessment through discursive and reflective essays drawing on the thinking experience are valued.

The study findings contribute to the business education literature in several ways. First, this study answers the call for more work to "better chart the connections among theory, pedagogy, course enactment, and student perceptions of the learning environment" (Vess and 
Linkon, 2002, p. 107). Second, the findings will be important as the literature on interdisciplinary teaching and learning is comparatively much smaller than the literature on interdisciplinary research. Third, many researchers have examined the issues of learning in the field of business education, few explore the benefits of focusing on the practice of reflective learning when developing a management-development approach (Higgins, 2011). Fewer explore the use of reflective-practice-based assessments in interdisciplinary settings. In sum, this study highlights the significance of integrating reflective practice in undergraduate business education to promote students' interdisciplinary thinking.

The paper is structured as follows. First, the paper discusses the literature pertinent to the study. Then the paper introduces the study design including the study context, the method used to evaluate COMM101 intervention, and data analysis methods. This will be followed by results of the survey study. The paper is concluded by providing a discussion on the findings, identifying study limitations, and implications for research and practice.

\section{Literature Review}

Interdisciplinary Teaching, Education and Learning (IDTEL)

It is important to understand what is meant by interdisciplinarity and distinguish its meaning with other related concepts. Rhoten and Pfirman (2007, p. 58) viewed interdisciplinary research as "the integration or synthesis of two or more disparate disciplines, bodies of knowledge, or modes of thinking to produce a meaning, explanation, or product that is more extensive and powerful than its constituent parts." Carr et al. (2018, p. 35) identify that this integration can "range from simple communication of ideas to the mutual integration of organizing concepts, methodology, procedures, epistemology, terminology, data and organization of research and education." In contrast, multidisciplinary research works on a common problem but from their 
own silos requiring cooperation rather than integrative collaboration (Siedlok and Hibbert, 2014). Transdisciplinary research on the other hand is a fusion of disciplines with increasing coherence of knowledge where boundaries between disciplines become trivial or are fundamentally reshaped (Siedlok and Hibbert, 2014).

These distinctions are important as some scholars can be either unaware or unconcerned about these subtle differences and can use these terms interchangeably (Knight et al., 2013). In a similar vein, Rylance (2015, p. 314) asserts that "interdisciplinary research that involves neighbor disciplines is much more common, and significantly easier to develop, than areas in which the disciplinary stretch is vast and the logistics and intellectual challenge more demanding."

Literature shows some examples of interdiciplinary business management education (e.g., Ducoffe et al., 2006; Lattuca et al., 2004) assessing whether the claims for interdisciplinary education are realized in practice. Ducoffe et al. (2006, pp. 277-278) refer to the AACSB's Management Education Task Force final report that identifies curricular relevance as a critical priority and the Task Force recommend that business schools "blur boundaries between educational disciplines. Cross-disciplinary programs facilitate market relevance by encouraging boundary spanning teaching and thinking" (AACSB, 2002) to ensure curricular relevance. Ducoffe et al. (2006, p. 282) examine ex-post students' perception of an interdisciplinary subject curriculum (BU100/BU200). For instance, they asked former alumni if they rated it higher in comparison to other courses and got the pleasing answer that it did for many students in different ways, e.g. "BU100/BU200 is a course I remember more than most courses I took in the School of Business" (74.6\% said yes). The authors claim that "the most powerful aspect of the course was the integration itself ... the level of success in weaving the subject matter together into an integrated presentation was crucial to postcourse perceptions." 
Mansilla and Duraising (2007) sought to identify how academics could "see" the "interdisciplinary thinking" in their students' work, and they came up with three dimensions disciplinary grounding, advancement through integration, and critical awareness. The interdisciplinary theory-in-use here is that students cannot manifest interdisciplinary understandings without first achieving disciplinary groundings. Thus the assessment should make the student apply disciplinary insights "using disciplinary theories, findings, examples, methods, validation criteria, genres, and forms of communication" (Mansilla and Duraising (2007, p. 222). The second dimension is the ability for students to integrate these disciplinary insights through a range of integrative devices (conceptual frameworks, graphic representations, models, metaphors, complex explanations, or solutions). The aim is to develop a more complex, effective, empirically grounded, or comprehensive accounts. Third is the ability for students to demonstrate "the purpose, reflectiveness, and self-critique" by "framing problems in ways that invite interdisciplinary approaches and exhibiting awareness of distinct disciplinary contributions" (Mansilla and Duraising, 2007, p. 222).

In some courses students were assessed on basic content first because thorough understanding of disciplinary concepts or methods was seen as a prerequisite for effective interdisciplinary work; “if they [students] don't have the basic understanding, they can't draw the links" (Mansilla and Duraising, 2007, p. 223). In the case of "advancement through integration" which is a more interdisciplinary dimension, dependent on prior "disciplinary grounding", one academic described the best interdisciplinary work as taking "a tool set from one discipline and very rigorously and thoroughly applying it in a place where its application was not invited or anticipated" (Mansilla and Duraising, 2007, p. 225).

A study by Newswander and Borrego (2009, p. 552), investigated "What specific practices or cultures are characteristic of successful interdisciplinary graduate education?" and the authors provide answers based on engagement. Recognizing some of the different meanings 
attached to the term "engagement", they follow Haworth and Conrad (1997) who use it to characterize programs in which students, faculty, and administrators are diverse and engaged in mutually supportive teaching and learning. The authors highlight the two themes of "interactive teaching and learning" and "connected program requirements". The interactive teaching and learning theme included the importance of seminars which students, faculty, and others could come together and share interdisciplinary knowledge and also provide chances to interact facilitating a participatory culture (Newswander and Borrego, 2009). The importance of the second theme of "connected program requirements" concerns a feature of the process where programs draw information and methods from a number of different traditional academic disciplines. There are several criticisms of interdisciplinarity in general and interdisciplinarity in management education in particular.

One criticism of interdisciplinarity is its vulnerability to external influences from corporate and political agendas. Interdisciplinarity can become a "source of legitimation" for corporate-style institutional arrangements and can raise issues on "the sources of its funding, and the social, political, and economic implications of the 'solutions' it offers" (Hearn, 2003, p. 10). Interdisciplinarity, according to Hearn (2003, p. 10), thus can function as a "Trojan horse, smuggling external political and economic interests inside the wall of the academy" and used to develop "entrepreneurial conceptions of 'good' academic conduct" (Cannizzo, 2016, p. 881).

Interdisciplinarity can also fall victim to a self-confirming prophecy, that it will "never be fully acknowledged even though it holds so much promise" (Lindvig and Ulriksen, 2020, p. 57). Using Said's argument of othering the Orient by Western scholars, proponents of monodisciplinarity write about interdisciplinarity in the same exotic way the Orient can be explained by Western scholars, thus appearing as inferior and much less developed than monodisciplinarity. Lindvig and Ulriksen (2020, p. 714) argue that not only is this 'othering' 
done by proponents of disciplines to interdisciplinary, by emphasizing that interdisciplinarity is different from everyday disciplinary teaching and learning activities, "interdisciplinarity is othered". Furthermore, "monodisciplinarity, as the binary opposite to interdisciplinarity, will be perceived as the more constant and grounded phenomenon" (pp. 714-715). Lastly, rather than teaching, coordination and curriculum practices, institutional processes have been found as primary obstacles to interdisciplinary education (Hannon, Hocking, Legge and Lugg, 2018), showing the complex challenges in implementing interdisciplinarity effectively.

There are also several specific challenges to interdisciplinarity in management education. According to Palmer (2002), management discipline is different and more problematic due to three issues: disciplinarity, classification and focus. They argue that first, the management discipline consists of several sub-disciplines. And it is not a clearly defined body of knowledge with its own knowledge verification methods. On the contrary, it includes various co-existing components of other disciplines. Thus, it is more multidisciplinary in nature. Second, the management discipline is considered as holding a lower position in the epistemological pecking order (Macfarlane, 1995, p. 3). It is more focused on promoting professional practice targeting developing guidelines and procedures (Ryan and Neumann, 2013; Becher 1989; Neumann, Parry and Becher, 2002). Third, the focus of the discipline is not one of convergence of its subdisciplines (as in medicine, which has a higher academic status). Management discipline is known to project a divergence of sub-disciplines because it is broadly concerned with the 'management of business' at the individual, group, firm, national and global levels. According to Becher (1989), the more convergent various sub-disciplines in a field, the more status it has in academe.

Ryan and Neumann (2013) argue well that even with the obvious draw backs highlighted above, management education has come to be a great market success story due to its global marketability. Universities have been selected by various governments as dominant players in 
economic growth (Jarvis, 2001; Olssen and Peters, 2005). However, with declining government funding to university sector, business studies in universities have been a key driver in the globalization of higher education (OECD, 2007). Due to potential revenue risks, such globally market driven education of management graduates presents complex challenges to academics wanting to alter the original structure of the curriculum. Thus, to advance interdisciplinarity in business studies, Ryan and Neumann (2013) argue that the context of university setting should promote a common focus, opportunities to communicate and feelings of ownership.

Despite the above, a large body of literature support the idea that interdisciplinarity is a good idea for higher education and business education. However with the exception of Ducoffe et al.'s (2006) study, we were unable to find studies that explore how interdisciplinary courses impress students and, more interestingly, what features of such courses contribute the most in achieving business students' learning outcomes. In the absence of consensus amongst prior studies involving management students' engagement with interdisciplinary teaching and learning, the study drew on Spelt et al. (2009) which offers a process model to examine how educational design can produce interdisciplinary thinking. According to Spelt et al.'s (2009) interdisciplinary learning framework, students' interdisciplinary thinking is influenced by factors in the student, the learning environment and the learning process. For Spelt et al. (2009), student engagement is an emergent rather than a designed aspect in the learning process. The authors identify several subskills and conditions for interdisciplinary learning including student characteristics, characteristics of learning environment, aspects of the learning process, and the relationships between student, learning environment and learning process. 


\section{Research Design and Methods}

\section{Study Context and Hypotheses}

The University of Wollongong in which the research is conducted is one of over 40 accredited universities in Australia. By 2012-13 the support for interdisciplinary teaching at this university had grown and, supported by the central management team, a vote in Senate recommended that the university as a whole should develop a more systematic approach to interdisciplinary teaching and learning amongst other things. This approach was made more systematic with the "Curriculum Development Project" (CDP, anonymized) which became the focus of a university-wide consultation process in 2013. This project was understood as a process for renewing the university's curriculum to guide a four-year plan to review all courses. In a subject development meeting, it was advocated that a new first year core subject be established on ethics and responsible business and focusing on the consequences of managerial and executive action on individuals, organizations and society (see also Fernando, 2011). Hence, the subject COMM101 was designed. This study aims to test the following hypotheses: $H_{0}$ : Mean survey scores representing interdisciplinary thinking will not change as a result of introducing reflective assessment methodologies between cohort years.

$H_{1}$ : Mean survey scores representing interdisciplinary thinking will improve as a result of introducing reflective assessment methodologies between cohort years.

\section{Data Collection}

During 2014 and 2015 under the auspices of the CDP and the new curriculum model, there was a renewed effort to study the impact of some decisions made in this period. The present paper focuses on the period of consultation 2014-15. The present study follows a pilot study 
conducted in 2013 on "bottlenecks" (Middendorf and Pace, 2004) to interdisciplinary teaching and learning in COMM101. The pilot study findings from lecturer and teaching assistant interviews indicated low integration of disciplinary content and student disengagement (see Fig. 1). The best way to characterize the methodology followed by the lead author in this period is "action research" or more specifically, what Coghlan (2001) calls "insider action research". It can be identified in two types: mechanistic- and organistic-oriented insider action research (Coghlan, 2003). That is, some methods from the questionnaire survey tradition of action research practitioners such as Burleigh Gardner in Whyte's account (mechanistic-oriented) and some methods better described as 'self-ethnography' (organistic-oriented) such as how university lecturers study themselves teaching and their students learning in the everyday course of observing things while doing them (Brannick and Coghlan, 2007; Alvesson 2003, 2007). The findings of the insider action research phase indicated student engagement was one of the main "bottlenecks" to promoting interdisciplinary thinking in COMM101.

Based on the results of this preliminary research phase, ethics-based content was used to promote interdisciplinary thinking in the subject. The teaching team undertook a series of pedagogical revisions to promote disciplinary integration and interdisciplinary thinking. The formal COMM101 lecture topics included ethical challenges in managing a range of global issues relating to the environment, globalization, technology, anti-corruption, labor and human rights. Students examined these issues from a variety of moral philosophies and applied them across a range of domains including marketing, operations, human resources, accounting and finance. In the first lecture, the lead coordinator would conduct a 'show of hands' survey on the representation of cultures in the lecture theatre and make a note to draw culturally aligned examples during the session.

\section{Insert Figure 1 here.}


Based on the pilot study findings, a wider study was developed to examine the effect of these pedagogical revisions on the student experience of interdisciplinary thinking, including their level of engagement with it. To do this, the study drew on Spelt et al. (2009) whose main contribution was to identify the subskills and conditions necessary to develop "interdisciplinary thinking." Using Spelt et al.'s (2009) conceptual framework, this project developed a case study-based reflective essay which was introduced in 2015 to compare the cohorts before 2014 and after 2015 in order to assess the effect of the intervention. According to this framework, students' interdisciplinary thinking is influenced by factors in the student, the learning environment and the learning process. All the variables and corresponding constructs in the framework are interwoven to create an effective interdisciplinary learning environment to promote interdisciplinary thinking.

In 2014-15, COMM101 had two in-session assessments and a final written examination. The first assessment (formative) was a weekly homework write-up. The second assessment was a case-study-based reflective essay. The case-study approach was expected to promote interdisciplinary thinking. In each teaching session, a new and topical case study would be used for the assessment. Use of case studies may be very beneficial in interdisciplinary subjects, as they allow students to apply multiple areas of reasoning to one problem. Reflective practice promotes experiential learning by giving students the opportunity and to integrate their own experiences into their understanding of a topic (O'Connell and Dyment, 2011). To promote interdisciplinary thinking, Spelt et al. (2009) note that student's personal characteristics and their prior experiences both need to be considered. These researchers note that "provoking students in contrasting and conflicting disciplinary perspectives combined with developing a critical stance seems to be essential to stimulate students to depart from their notion of absolute knowledge" (Spelt et al., 2009, p. 374). From this framework, a questionnaire representing the 
items in Appendix 1, plus two open-ended questions, was developed to gather data on students' experiences of COMM101 in the Autumn 2014 and Autumn 2015 teaching sessions.

Following a first survey round in COMM101 (Autumn 2014), the intervention was introduced in Autumn 2015, followed by a post-intervention survey. The survey was administrated in paper form by a research assistant who was not associated with the teaching or administration of COMM101. It was distributed in the week 10 tutorial for both the 2014 and 2015 cohorts and was collected at the end of the same class. The survey consisted of items representing each of the key variables in the framework. Items were designed to represent the key themes identified by Spelt et al. (2009) (Appendix 1). Respondents were asked to answer both closed-ended ("yes" and "no") questions and open-ended questions. This format was used due to the time limitation of accessing students during the one-hour COMM101 tutorial classes. Prior to the data collection, approval was taken from the Human Research Ethics Committee of the university to conduct the study and participants provided written informed consent to participate in the study.

In total, 510 students participated in the study: 260 in Autumn 2014 and 250 in Autumn 2015 (Table 1). Students from 2015 were slightly younger. Students' longest work experience was between three and four years for the 2015 cohort, but less than one year for the 2014 cohort. The proportion of Australian students increased from 57\% (2014) to 64\% (2015) and that of Chinese students decreased from $22 \%$ (2014) to $17 \%$ (2015). For both years, the most-often reported motivation to study in the higher-education sector was job and career opportunities, followed by interest, enjoyment, passion and money. Overall no significant or noticeable differences were observed between students from each year that would need to be included as a covariate in subsequent analyses between groups.

\section{Insert Table 1 here.}




\section{Data Analysis}

The survey data was analyzed using SPSS. Before analyzing survey responses, demographic characteristics including age, years of employment, nationality and study type (full-time vs part-time) were compared between groups using independent samples t-tests and chi-squared tests (for study type and nationality). For each of the 36 survey items, the percentage of "yes" responses were compared between samples (2014 and 2015) using Pearson's Chi-squared tests. Survey items where then grouped in to their relative constructs including: Having knowledge (items B1-B9), having skills (B5-B6), curriculum (D1-D2), teacher (D3-D8), pedagogy (D9D10), assessment (D12), learning pattern (E1-E3), and learning activities (E4-E7). For each of these constructs the mean number of "yes" responses were aggregated and compared between groups using an independent samples t-test. Before conducting these comparisons assumptions of normality and homogeneity of variance were checked using Shaprio-Wilk and Levene's tests respectively. These assumptions were not violated for any data set compared. Given the type of data and the simple comparative nature of the study design, this study considered these statistical methods most appropriate for this study given that the assumptions underpinning them were not violated.

\section{Results}

\section{Student Variable}

Spelt et al. (2009) note that two conditions influence students towards interdisciplinary thinking; personal characteristics and prior experiences. Personal characteristics were assessed using six items: curiosity, respect, openness, patience, diligence and self-regulation (items $\mathrm{C} 1$, C2, C3, C4, C5 and C6 respectively). Despite the decrease in the proportion of Chinese students in the 2015 cohort by 5\%, and the increase in the proportion of Australian students by $7 \%$, 
comparison of items relating to students' personal characteristics revealed no statistically significant differences across all items including in the cultural dimension in the responses. Given that skills deficits have been reported in business education students to effectively use language and coherence in writing, and to understand, present and solve problems (Calma, 2013), the absence of any such statistically significant difference is surprising. However, it could be because the subject has no group-based assessments where the cultural and language aspects could have been otherwise more pronounced. Overall, students' personal characteristics indicated a relative increase of all six items from 2014 to 2015 . The second construct in Spelt et al.'s (2009) student variable is prior experience. This was assessed through two items: social experiences (C7) and educational experiences (C10). Comparison of items relating to prior experiences of students revealed no statistically significant differences across both items.

\section{Interdisciplinary-Thinking Variable}

The variable of interdisciplinary thinking contains the attributes of having knowledge and having skills. Having knowledge was evaluated through three items: knowledge of disciplines (B1 and B2), knowledge of disciplinary paradigms (B3 and B4) and knowledge of interdisciplinarity (B7, B8 and B9). Overall, no significant increases or decreases in "yes" responses were observed between 2014 and 2015 for any item in the "having knowledge" construct. The mix of slight increases and decreases across items between years suggests that differences are random fluctuations, and not related to the year of study. Notably, there was low agreement to item B4, "I often feel overwhelmed by the subject content". High agreement was observed for most other items except for B1, "I know the differences between disciplinarily, multidisciplinary and interdisciplinary", and B7, "learning that integrates knowledge from different disciplines across a central theme or focus", for which only moderate 
levels of agreement were observed. These results are understandable given that most COMM101 students are in their first university session. The interdisciplinary-thinking variable includes a second construct of having skills, which was assessed through two items B5 and B6. Although item B5 showed no significant increase in 2015, the number of "yes" responses to item B6 ("I have the communication skills necessary to appreciate the language of different disciplines...") increased significantly from $76.2 \%$ agreement to $83.7 \%$ agreement, with significance determined by a chi-squared test $(r=4.38, p=.036)$.

\section{Learning-Environment Variable}

Almost all items relating to curriculum, teacher, pedagogy, assessment and learning-pattern and learning-activity constructs showed no significant increase in "yes" responses in 2015. One exception was observed under the pedagogy construct, item D10, "COMM101 content is aimed at achieving active learning", for which there was a significant $10.6 \%$ increase in "yes" responses, from $86.5 \%$ in 2014 , to $97.1 \%$ in 2015 , as determined by a chi-squared test $(r=$ $18.34, p=.000)$. For most other items, the percentage of "yes" responses showed an increase over time; however, this increase was typically very small, averaging out at $1.7 \%$. This finding is understandable given that COMM101 has no group-work-based assessments. Furthermore, it should be noted that most items had an agreement of at least $70 \%$ across both years, excluding item D11, "COMM101 content is aimed at achieving student collaboration", for which an agreement of $68.8 \%$ was observed for students in 2014.

\section{Differences between Construct Averages}

The number of "yes" responses was averaged across the items within each of the seven constructs to calculate seven composite scores. These scores were compared between 2014 and 
2015 using an independent-samples t-test. All but one of these constructs showed an increase an average number of "yes" responses from 2014 to 2015, but only one of these increases was significant. The results show significant differences $(\mathrm{p}<0.05)$ in terms of pedagogy between 2014 and 2015. An increase in responses to D10 (active learning) is the main contributor to this result. In 2015, the reflective essay required students to make connections between their week 3 tutorial in-class submission regarding the question "What does the term 'responsible business' means to you?", and on the learning that occurred until the submission of the reflective essay in week 11. It is likely that this process encouraged the 2015 cohort to appreciate the learning that had occurred during the session and how it had occurred, and particularly how newly acquired knowledge between the week 3 submission and the week 11 submission of the reflective essay had altered their existing knowledge. In the 2015 week 3 lecture, "Is Responsible Business Important?" the teaching and learning challenges of COMM101, past cohort grade distributions and the learning and unlearning processes to which students would be exposed in COMM101 were explained. These initiatives are the most likely causes for active learning (D10) to show a significant positive difference in 2015 . The means between years for each construct are presented in Table 2, and graphically in Figure 2.

\section{Insert Table 2 here.}

\section{Insert Figure 2 here.}




\section{Other Findings}

To obtain an overall view of the student perceptions on the interdisciplinary learning of COMM101, participants were asked to answer two open-ended questions; Tables 3 and 4 show the responses in ranking order for each year in terms of the seven most frequent responses.

Table 3 summarizes student responses on what factors made their interdisciplinary learning situations more engaging. The most notable is the rise in rank of "Integrating knowledge from disciplines" from sixth in 2014 to third rank in 2015. The case-study-based reflective essay intervention could have been a contributory factor for this rise in 2015 .

\section{Insert Table 3 here.}

Table 4 summarizes student responses on the most challenging barriers to learning in COMM101. The most notable is the drop in "motivation and relevance" from being the most common barrier to learning COMM101 in 2014 to the least in 2015. Having students "thinking about thinking" through the reflective essay intervention could have contributed to this result. Moreover, as noted earlier, an interdisciplinary learning experience mirrors more closely that of "real-life" management practice. Hence, heightened interdisciplinarity in the subject could be expected to multiply relevance and motivation.

\section{Insert Table 4 here.}

\section{Discussion}

The study results highlight the significance of integrating reflective practice in undergraduate business education to promote students' interdisciplinary learning. There are several causal models of the factors that matter to the achievement of interdisciplinary learning outcomes 
(e.g., Harper and Lattuca, 2010; Mansilla, 2005; Spelt et al., 2009). One of the benefits of creating and testing models in research, is that as models are compared, it becomes progressively clearer which factors count most. And clarity can be a problem in studies of interdisciplinarity. As Mansilla (2005, p. 16) mentions:

"Lack of clarity about indicators of quality is particularly evident in the assessment of student interdisciplinary work - where both the underlying nature of interdisciplinary understanding and how it might be recognized remain insufficiently defined. What does it mean to deeply understand an issue in an interdisciplinary way? How is it different from deep disciplinary understanding or a superficial merging of viewpoints?"

The language of factors, causality and outcomes is a way of starting to understand complex relations between student characteristics, conditions within their environment and subject content. This study used a detailed insider account of the short history of COMM101, its context and changes past and present, plus a snap-shot of two cohorts of student responses to help make sense of which changes to COMM101 seem to have improved student engagement with its interdisciplinary subject matter.

Accordingly, we suggest that the Spelt et al.'s (2009) model could be extended to reflect the findings of this study bearing out the links between reflective practice and interdisciplinary thinking. For example, the Spelt et al. (2009) framework was primarily developed on the theory of Biggs (2003). It was used to develop and categorize subskills and conditions. Other seminal theories such as Transformative Learning (Mezirow, 2000) could be integrated to develop a more inclusive and rigorous theoretical representation of teaching and learning across the curriculum. Additionally, the literature search could be varied to integrate more languages and scientific literature databases to further develop the theoretical framework.

The results support $\mathrm{H}_{1}$ showing that introducing the case-study-based reflective essay intervention improved interdisciplinary thinking. Of the student characteristics that influence 
interdisciplinary thinking in Spelt et al.'s (2009) framework, all six items grouped under students' personal characteristics increased from 2014 to 2015. Similar to Harper and Lattuca (2010), as the session progressed, COMM101 students' average assessment marks increased. However, the additional emphasis in lectures and tutorials on reflective essay writing could have brought about this result (i.e., by increasing the level of curiosity). The learningenvironment conditions variable showed a relative increase in all items, but "COMM101 content is aimed at achieving active learning" (D10) showed a statistically significant increase in "yes" responses. In active learning, students are expected to employ the learning domains of knowledge, skills and attitudes. They are not passive listeners, they become active readers, writers, discussants and engaged in problem-solving. Active learning students must engage in such higher-order thinking tasks as analysis, synthesis, and evaluation (Auster and Wylie, 2006). Thus the statistically significant increase of D10 could indicate increased student engagement because active learning is about "doing things" and "thinking about the things they are doing" rather than passive participation.

The associated learning support provided through the teaching staff and the online dedicated subject website could have also contributed to this increased active learning finding. The support emphasized that students should engage in the reflective essay writing process early in the session and should write several iterations of the reflective essay before submission. In a dedicated lecture, students were informed about the interdisciplinary nature of the subject and were exposed to Kolb's (2014) reflective-practice model. Support material on reflective practice and how to write a reflective essay were posted on the dedicated subject website. A scaffolding approach was used in which the student was required to submit an initial response at the beginning of the session and reflect on that response to write the reflective essay later in the session. The emphasis placed on this process of case-study-based reflective essay writing could have contributed to the increase in "yes" responses to D10. 
The study aligns with Mansilla and Duraising (2007, p. 230) in not asking "how much of integration is enough?" but rather "what is the cognitive and practical purpose of this work, and is this integration advancing it in disciplinary grounded and reflective ways?" As others have noted, reflective ways or practices matter a good deal (Hibbert and Cunliffe, 2015). The study justifies this view based on representative evidence on the teaching and learning of COMM101. For example, student evaluations frequently comment that the lecturer "interact[s] with the class, often challenging me to re-valuate my views and how I think". Also peer review reports often on the teaching of COMM101 comment on the reflective and practical relevance of the subject and teaching approach. These reports particularly highlight extensive use of real world examples to promote reflexivity (for example, using business scandals, see Fernando, and $\operatorname{Sim}, 2011)$.

Although the number of significant differences was small, the high level of agreement with statements overall is encouraging support for the quality of the subject across both years. The only statement with relatively low agreement (item D11, collaborative learning) may indicate that this area could be improved. This finding can be expected because the current offer of the subject does not include any group-based assessments. The value of collaborative learning in interdisciplinary settings has been emphasized by various scholars, and this will be a consideration for further development of COMM101. In the development of group-based assessments, the influence of student's cultural context on collaborative learning will need to be considered.

\section{Limitations}

While the same student cohort was not tracked over time, the two cohorts compared were both from Autumn semesters (i.e. the first of two annual semesters), allowing as much cohort similarity as possible. The Autumn student cohort for COMM101 usually consists of first-year, 
first-semester university entrants with only about $5 \%$ of the cohort coming into the subject via a different route. So typically, the clear majority of students is just out of high school and is exposed to university life for the first time. It could be questioned (a) if the first semester of the students' first year at university, is the best time to introduce them to interdisciplinary studies; and (b) whether it might be better to study them in their second or third year? Given that the university had decided to start interdisciplinary studies in the first year, it was considered appropriate to do the study, but it is possible that the results might be stronger if a similar study was done on third-year capstone course students. While no significant differences were observed between cohorts in regards to demographic differences, some potential demographic covariates (such as gender) were not observed or controlled in the statistical model. Furthermore, due to the absence of a group-based assessment in the subject, although the cohort was represented by a sizable number of non-Australian students, the cultural influence on collaborative learning was not examined.

Another limitation was that the trial was limited to only two student cohorts. A longerterm study involving additional student cohorts could have revealed more robust and consistent results. While there were slight increases in "yes" responses for various measures, most were not significant. It is possible that this was due to the yes/no response format; future studies could investigate the effects of a more sustained intervention, assessed using Likert-type questions. First-year business students may also find the terminology used in this study both unfamiliar and complex. However, the open-ended questions were introduced to give students an opportunity to reveal any confusion and misunderstanding. Finally, it should be noted that the generalizability of this sample to the broader business student population may be limited given the relatively small sample size. However, the sample is from a subject offered in two similar sessions (Autumn) in an Australian university with typical first-year undergraduate 
business student attributes. Therefore, these findings would be particularly applicable to such a student cohort.

\section{Practical Implications}

There are several practical implications from this study that can be helpful for teachers and curriculum designers of interdisciplinary subjects. First, the study findings verify the value of the Spelt et al.'s (2009) model, and extends their work to suggest that some modes of reflective practice are especially beneficial, particularly when embedding a scaffolding approach in the assessment structure. Such an approach can create forms of feedback based on learner experiences and reflections over time. Second, the study shows how an ethical problem was framed in a way to evaluate the degree to which students' work exhibits a clear sense of purpose, reflectiveness and self-critique. The use of a disciplinary boundary spanning theme like ethics as the integrator through a case-study-based reflective learning activity can help promote student engagement and interdisciplinary thinking. Framing problems in this way that invite interdisciplinary approaches could create opportunities for students to exhibit the three dimensions of interdisciplinary assessments; awareness of distinct disciplinary content, demonstrate how the overall integration "works," and the limitations of the integration (Mansilla and Duraising, 2007).

Second, interdisciplinary course coordinators should constantly seek ways to promote the relationships between student, learning environment and learning process conditions to better influence interdisciplinary thinking. Acting on a continuous quality assurance process by undertaking curriculum development with a view to enhancing interdisciplinary thinking and student engagement to review the impact on the student, learning environment, learning process and learning outcomes is vital for the subject to remain relevant. Although not highlighted in this study, collaborative learning activities through group work could introduce 
a cultural aspect to interdisciplinary learning, particularly in cohorts where there is greater student diversity.

Finally, the study recommends the use of reflective practice in interdisciplinary subjects to support a variety of learning outcomes across disciplines. Reflective practice is particularly useful when large class size or other factors limit the opportunities for social learning by students outside the classroom. The case-study-based reflective essay intervention shows that students perceive the experience as involving more active learning. Even though students may know how to act in an ethical way, there is little evidence to suggest that they will act in such a manner in real-world business settings. Chia and Holt (2008) suggest that this is because management education is naturally disengaging, because teaching occurs from a disengaged, positivistic position, with an emphasis upon stereotypes and categorical imperatives rather than engaged, situated responses to unique ethical dilemmas. While reflection is often considered a withdrawn, academic activity, it can also be a deeply social process, perpetuated by differences between students that can both engage students and repel them from each other. Thus it could be argued that by using active/experiential approaches, students are not schooled in treating ethical behavior as abstract and standalone; rather, they become experienced in negotiating boundary spanning topics such as ethics through normal, everyday interactions by engaging in subject content and case studies.

\section{Conclusion and Future Research}

The study findings extend Spelt et al.'s (2009) model. Other seminal theories such as Haworth and Conrad's (1997) engagement theory and transformative learning theory (Mezirow, 2000) could be integrated to develop a more inclusive and rigorous theoretical representation of teaching and learning across the curriculum. While higher-education institutions have struggled to prepare students for diverse, interdisciplinary futures due to issues of engagement 
linked to the way subjects are taught, this paper responds to this challenge, albeit with preliminary findings. It shows that integral to engaging students in interdisciplinary learning is a need for more experiential and active approaches that limit how disengagement is built into education itself. Thus, this approach is more relevant to preparing managers for the contemporary workplace because by mixing ethical and economic concerns in the same case study, it imitates the social, messy, interdisciplinary nature of actual management practice (Currie et al., 2016; Ryan and Neumann, 2013). This approach does not reproduce disengagement institutionally within the design of courses; instead, it engages students with subject content and methods of learning embedded in the normal higher-education experience.

A further point here, is that having studied student responses to the case material, future research should pay more attention to what Mansilla et al. (2016) call "shared cognitiveemotional-interactional platforms" as both markers of interdisciplinary work and as pedagogical conditions for it. What seemed to account for the increase in student engagement between years 2014 and 2015, was the combination of: (a) ethical subject matter, both the need to address issues of ethical fairness in business and its emotional aspect (though this was common to both cohorts); coupled with (b) the change in tutorial practices during 2015, which gave time for students to think through lecture material each week and actively draft notes that could contribute to the essay due in week 11. This recalls the two themes of "interactive teaching and learning" and "connected program requirements" in Newswander and Borrego (2009). From the analysis of the survey and the description of how COMM101 differed in 2015 compared with 2014 , it could be argued that the change to tutorial activities constituted a different set of reflective practices than in 2014. Reflective practices that more persistently focused on the interdisciplinary essay assignment, enabling students to better address the issues. And while they still wrote individual essays, the tutorial exercises permitted much more 
discussion and interaction between students and the staff team as they actively made sense of the case study and did so over time.

Declaration of Conflicting Interests: The Authors declare that there is no conflict of interest. Funding: This research received no specific grant from any funding agency in the public, commercial, or not-for-profit sectors.

\section{References}

Ackoff, R. and Emery, F. (1972), On purposeful systems: An interdisciplinary analysis of individual and social behavior as a system of purposeful events. Aldine-Atherton, Chicago.

Alvesson, M. (2003), "Methodology for close up studies-Struggling with closeness and closure", Higher Education, Vol. 46, pp. 167-193.

Auster, E. R. and Wylie, K. K. (2006), "Creating active learning in the classroom: A systematic approach", Journal of Management Education, Vol. 30 No. 2, pp. 333-353.

Brannick, T., and Coghlan, D. (2007), "In defense of being 'native': The case for insider academic research”, Organizational Research Methods, Vol. 10 No. 1, pp. 59-74.

Becher, T. (1989), Academic tribes and territories: Intellectual enquiry and the cultures of the disciplines, Open University Press, Buckingham.

Biggs, J. (2003), Aligning teaching and assessment to curriculum objectives, ITSN Generic Centre, Learning and Teaching Support Network.

Brint, S. G., Turk-Bicakci, L., Proctor, K. and Murphy, S. P. (2009), "Expanding the social frame of knowledge: Interdisciplinary, degree-granting fields in American colleges and universities, 1975-2000", The Review of Higher Education, Vol. 32 No. 2, pp. 155-183. 
Buttermore, J. A. (2011), "The team-taught cross-functional core: Insights from a long-term undergraduate program", Journal of Education for Business, Vol. 86 No. 4, pp. 240247.

Calma, A. (2013), "Fixing holes where the rain gets in: Problem areas in the development of generic skills in business", Journal of International Education in Business, Vol. 6 No. 1, pp. 35-50.

Campbell, N. D., Heriot, K. C. and Finney, R. Z. (2006), "In defense of silos: An argument against the integrative undergraduate business curriculum", Journal of Management Education, Vol. 30 No. 2, pp. 316-332.

Cannizzo, F. (2016), “The transformation of academic ideals: An Australian analysis", Higher Education Research \& Development, Vol. 35 No. 5, pp. 881-894.

Carr, G., Loucks, D. P. and Blöschl, G. (2018), "Gaining insight into interdisciplinary research and education programmes: A framework for evaluation", Research Policy, Vol. 47 No. 1, pp. $35-48$.

Chia, R. and Holt, R. (2008), "On Managerial Knowledge", Management Learning, Vol. 39 No. 2, pp. 141-158.

Clegg, S. R. and Ross-Smith, A. (2003), "Revising the boundaries: Management education and learning in a postpositivist world", Academy of Management Learning \& Education, Vol. 2 No. 1, pp. 85-98.

Coghlan, D. (2001), “Insider action research projects: Implications for practising managers”, Management Learning, Vol. 32, pp. 49-60.

Coghlan, D. (2003), "Practitioner Research for organizational knowledge: Mechanistic-and organistic-oriented approaches to insider action research", Management Learning, Vol. 34 No. 4, pp. 451-463. 
Currie, G., Davies, J. and Ferlie, E. (2016), "A call for university-based business schools to "Lower Their Walls:" collaborating with other academic departments in pursuit of social value", Academy of Management Learning \& Education, Vol. 15 No. 4, pp. 742755.

Ducoffe, S. J. S., Tromley, C. L. and Tucker, M. (2006), "Interdisciplinary, team-taught, undergraduate business courses: The impact of integration", Journal of Management Education, Vol. 30 No. 2, pp. 276-294.

Fernando, M. and Sim, A. B. (2011), “Strategic ambiguity and leaders' responsibility beyond maximizing profits”, European Management Journal, Vol. 29 No. 6, pp. 504-513.

Fernando, M (2011), “A social innovation based transformative learning approach to teaching business ethics”, Journal of Business Ethics Education; Vol. 8, pp. 119-138.

Hannon, J., Hocking, C., Legge, K. and Lugg, A. (2018), "Sustaining interdisciplinary education: Developing boundary crossing governance", Higher Education Research \& Development, Vol. 37 No. 7, pp. 1424-1438.

Harper, B. J. and Lattuca, L. R. (2010), "Tightening Curricular Connections: CQI and Effective Curriculum Planning", Research in Higher Education, Vol. 51 No. 6, pp. 505-527.

Haworth, J. G. and Conrad, C. F. (1997), Emblems of Quality in Higher Education. Developing and Sustaining High-Quality Programs, Allyn and Bacon, Boston.

Hearn, A. (2003), "Interdisciplinarity/extradisciplinarity: On the university and the active pursuit of community”, History of Intellectual Culture, Vol. 3 No. 1, pp. 1-15.

Hibbert, P. and Cunliffe, A. (2015), "Responsible management: Engaging moral reflexive practice through threshold concepts", Journal of Business Ethics, Vol. 127 No. 1, pp. 177-188.

Higgins, D. (2011), "Why reflect? Recognising the link between learning and reflection", Reflective Practice, Vol. 12 No. 5, pp. 583-584. 
Jarvis, P. (2001). “Universities and corporate universities”, Kogan Page, London.

Knight, D. B., Lattuca, L. R., Kimball, E. W. and Reason, R. D. (2013), "Understanding interdisciplinarity: Curricular and organizational features of undergraduate interdisciplinary programs", Innovative Higher Education, Vol. 38 No. 2, pp. 143-158.

Kolb, D. A. (2014), Experiential learning: Experience as the source of learning and development, Pearson Education, Upper Saddle River, NJ.

Lattuca, L. R., Voigt, L. J. and Fath, K. Q. (2004), "Does interdisciplinarity promote learning? Theoretical support and researchable questions", The Review of Higher Education, Vol. 28 No. 1 , pp. 23-48.

Macfarlane, B. (1995), "Business and management studies in higher education: The challenge of academic legitimacy", International Journal of Education Management, Vol. 9 pp. 4-9.

Mansilla, V. B. (2005), "Assessing student work at disciplinary crossroads", Change: The Magazine of Higher Learning, Vol. 37 No. 1, pp. 14-21.

Mansilla, V. B. and Duraising, E. D. (2007), "Targeted Assessment of Students' Interdisciplinary Work: An Empirically Grounded Framework Proposed", The Journal of Higher Education, Vol. 78 No. 2, pp. 215-237.

Mansilla, V. B., Lamont, M. and Sato, K. (2016), "Shared cognitive-emotional-interactional platforms: markers and conditions for successful interdisciplinary collaborations", Science, Technology, \& Human Values, Vol. 41 No. 4, pp. 571-612.

Mezirow, J. (2000), Learning as transformation: critical perspectives on a theory in progress. Jossey-Bass Publishers, San Francisco, CA.

Middendorf, J. and Pace, D. (2004), "Decoding the disciplines: A model for helping students learn disciplinary ways of thinking", New Directions for Teaching and Learning, Vol. 2004 No. 98, pp. 1-12. 
Millar, V. (2016), "Interdisciplinary curriculum reform in the changing university", Teaching in Higher Education, Vol. 21 No. 4, pp. 471-483.

Neill, C., Corder, D. and Cox, K.W.S (2017), "Embracing the muddle: Learning from the experiences from interdisciplinary teaching and learning collaboration”, New Zealand Journal of Teachers' Work, Vol. 14 No.2, pp. 136-154.

Neumann, R., Parry, S., and Becher, T. (2002). "Teaching and learning in their disciplinary contexts: A conceptual analysis”, Studies in Higher Education, Vol. 27, pp. 405-417.

Newswander, L. K. and Borrego, M. (2009), "Engagement in two interdisciplinary graduate programs", Higher Education, Vol. 58 No. 4, pp. 551-562.

O'Connell, T. S. and Dyment, J. E. (2011), "The case of reflective journals: is the jury still out?", Reflective Practice, Vol. 12 No. 1, pp. 47-59.

OECD (1972), "Interdisciplinarity: Problems of teaching and research in universities", Washington, D.C.

OECD (2007), Education at a glance, 2006. Paris: OECD.

Olssen, M., and Peters, M. A. (2005), "Neoliberalism, higher education and the knowledge economy: From free market to knowledge capitalism", Journal of Education Policy, Vol. 20, pp. 313-345.

Palmer, G. (2002) "Management and business studies: Pressures from changing academic markets", Journal of Australian Studies, pp. 127-145.

Rhoten, D. and Pfirman, S. (2007), "Women in interdisciplinary science: Exploring preferences and consequences", Research Policy, Vol. 36 No. 1, pp. 56-75.

Ryan, S. and Neumann, R. (2013), "Interdisciplinarity in an era of new public management: a case study of graduate business schools", Studies in Higher Education, Vol. 38 No. 2, pp. 192-206. 
Rylance, R. (2015), "Grant giving: Global funders to focus on interdisciplinarity", Nature News, Vol. 525 No. 7569, p. 313.

Shay, S. (2016), "Curricula at the boundaries", Higher Education, Vol 71, pp. 767-779.

Siedlok, F. and Hibbert, P. (2014), "The organization of interdisciplinary research: modes, drivers and barriers", International Journal of Management Reviews, Vol. 16 No. 2, pp. 194-210.

Spelt, E. J. H., Biemans, H. J. A., Tobi, H., Luning, P. A. and Mulder, M. (2009), "Teaching and Learning in Interdisciplinary Higher Education: A Systematic Review", Educational Psychology Review, Vol. 21 No. 4, pp. 365-378.

Vess, D. and Linkon, S. (2002), "Navigating the interdisciplinary archipelago: The scholarship of interdisciplinary teaching and learning", in Huber, M. T. and Morreale, S. P. (Eds.) Disciplinary styles in the scholarship of teaching and learning: Exploring common ground, AAHE, Washington, DC, pp. 98-117.

\section{Appendix 1: Survey items}

\section{Item Question}

B1 I know the differences between disciplinarity, multidisciplinarity and interdisciplinarity.

B2 I am able to identify the connections between different disciplinary content of economics, management, marketing, finance, accounting and operations.

B3 Adequate attention was given in COMM101 to enable me to step beyond my disciplinary based theories and methods.

B4 Due to the interdisciplinary nature of COMM101, I often feel overwhelmed by the subject content. 
B5 I have the necessary skills to search, identify, understand, critically appraise, connect, and integrate theories and methods of different disciplines.

B6 I have the communication skills necessary to appreciate the language of different disciplines in order to be able to negotiate meaning, resolve disciplinary differences, develop shared understanding, and communicate my ideas to a broad audience.

B7 Learning that integrates knowledge from different disciplines across a central theme or focus

B8 Learning that involves teaching and learning with students from different disciplinary backgrounds

B9 Learning that involves a transformative process allowing the connections between disciplines to emerge/become apparent.

C1 I am curious to learn new content from other disciplines.

C2 I am respectful of opinions of students from other disciplines.

C3 I am open to learn new ideas and concepts from other disciplines.

C4 I am generally considered by my family and friends as a patient individual.

C5 I am generally considered by my family and friends as a diligent individual.

C6 In times of adversity, I am able to control myself through self-regulation.

C7 I have been exposed to a considerable amount of social experiences through work, family, friends, community and sporting activities.

C10 My past disciplinary background provides an enriching context to my interdisciplinary study in COMM101.

D1 COMM101 balances various discipline based knowledge and interdisciplinary knowledge.

D2 COMM101 uses an overarching framework that links and sequences various teaching content. 
D3 Transition to interdisciplinary learning was well supported by lecturers and tutors.

D4 COMM101 teachers are experts at teaching interdisciplinary content.

D5 The COMM101 teaching team showed expertise and agreement on the interdisciplinarity of the subject.

D6 I believe that interdisciplinary team learning efforts are important to achieving effective interdisciplinary Learning.

D7 I value co-learning in COMM101 with students from different disciplinary backgrounds.

D8 COMM101 provides opportunities for student co-learning in an interdisciplinary context.

D9 COMM101 content is aimed at achieving interdisciplinarity.

D10 COMM101 content is aimed at achieving active learning (i.e. a process whereby students engage in activities, such as reading, writing, discussion or problem solving that promote analysis, synthesis and evaluation of class content).

D11 COMM101 content is aimed at achieving student collaboration.

D12 Though reflective practice, COMM101 has forced me to rethink my own assumptions.

E1 COMM101 helps me to learn content in a linear pattern (e.g., progressive topics presented in sequential order based on textbook chapters).

E2 COMM101 helps me to learn content in an iterative pattern (e.g., topics presented repeatedly).

E3 COMM101 helps me to learn content through milestones with encountering questions (e.g., learning outcomes that serve as milestones in which you were repeatedly exposed to interdisciplinary thinking). 
E4 COMM101 provoked me to develop a critical stance by contrasting different disciplinary perspectives.

E5 Due to COMM101, I have a better understanding of the strengths and limitations of disciplines other than my own.

E6 Interdisciplinary learning in COMM101 has enabled me to engage holistically with problems.

E7 Due to COMM101, I am able to communicate knowledge and ideas effectively across disciplinary boundaries. 